\title{
Effects of curcumin on pentylenetetrazole-induced anxiety- like behaviors and associated changes in cognition and monoamine levels
}

\author{
Jithendra Chimakurthy ${ }^{1,2}$ and Murthy Talasila ${ }^{1}$ \\ 1-Bapatla College of Pharmacy, Andhra Pradesh, Bapatla, India \\ 2-Acharya Nagarjuna University, Nagarjuna, Nagar, India
}

\begin{abstract}
The purpose of the present study was to estimate the protective effects of curcumin against anxiety and memory impairment, which are often comorbid in patients with anxiety disorders who are on standard anxiolytic therapy. The effects of curcumin on brain monoamine levels were also determined. We used the elevated plus maze (EPM), a standard animal model of anxiety, to determine the effects of subacute administration (14 days) of curcumin at doses of $5 \mathrm{and} 10 \mathrm{mg} / \mathrm{kg}$ (p.o.) against pentylenetetrazole (PTZ;20 mg/kg, i.p.)-induced anxiety-like behavior, followed by an evaluation of the effects of curcumin on cognitive deficits induced by PTZ using the passive avoidance retention task. Rats were exposed to the passive avoidance learning task before the initiation of treatment, and the effects on memory retention were studied $24 \mathrm{~h}$ after the EPM trial. A marked increase in the time spent in the open arms, an index of anxiety, and an increase in the step-down latency, an index of memory retention, were observed in curcumin-treated rats. Curcumin increased the levels of serotonin, norepinephrine, and dopamine in various regions of the rat brain. These results confirm the anxiolytic and memory-retentive effects of curcumin, and alterations in brain monoamine levels may have contributed to the present findings. Keywords: anxiety, memory, norepinephrine, dopamine, serotonin, curcumin.
\end{abstract}

Received 15 April 2010; received in revised form 18 June 2010; accepted 13 July 2010. Available on line 28 December 2010

\section{Introduction}

Anxiety has been conceptualized as a frequent and serious disorder affecting the world's population, independent of ethnicity, and is considered a cardinal symptom of many psychiatric disorders (Cassano, Pini, Saettoni, \& Dell'Osso, 1999). Psychopharmacological research has aided in the identification and treatment of anxiety disorders, such as generalized anxiety disorder, panic disorder, phobias, obsessive compulsive disorder, acute stress, and posttraumatic stress disorder. Many patients with these anxiety disorders are subjected to the adverse effects of drug treatments and present comorbid difficulties in memory and cognitive tasks (Eysenck \& Calvo, 1992).

Studies reporting the effects of Curcuma longa and curcumin in the treatment of psychiatric disorders are sparse and restricted to their effects on depression and stress (Xia, Cheng, Pan, Xia, \& Kong, 2007; Xu et al., 2005), monoamine oxidase A and B inhibition (Yu, Kong, \& Chen, 2002), learning and memory retention

Jithendra Chimakurthy and Murthy Talasila, Department of Pharmacology, Bapatla College of Pharmacy. Correspondence regarding this article should be directed to: Jithendra Chimakurthy. Department of Pharmacology. Bapatla College of Pharmacy, Bapatla Guntur (Dist.), Andhra Pradesh, Bapatla522 101, India. E-mail: jithu indra@rediffmail.com
(Ringman, Frautschy, Cole, Masterman, \& Cummings, 2005). Important studies have reported the effects of curcumin on brain serotonin (5-hydroxytryptamine, 5-HT) levels (Xu et al., 2005), the principle monoamine involved in the pathogenesis of many anxiety disorders, and norepinephrine (NE) and dopamine (DA) levels (Ferry, Roozendaal, \& McGaugh 1999; Aalto, Bruck, Laine, Nagren, \& Rinne, 2005). Rhizomes in Curcuma longa have been cited in the Database for Indian Medicinal Plants for the treatment of hysteria (Sharma, Yelne, Dennis, Joshi, \& Billore, 2002), which shares common fear- and emotion-related symptoms with typical anxiety. These studies make Curcuma longa an ideal choice for determining its effects on anxiety and associated memory impairment.

The treatment of different anxiety disorders depends on the type of anxiety disorder, varying from common anxiety to severe posttraumatic stress disorder. Drug therapy for generalized anxiety disorder includes benzodiazepines and buspirone (Wesolowska \& Nikiforuk, 2007). Treatment for obsessive-compulsive disorder includes selective serotonin reuptake inhibitors and tricyclic antidepressants (El Mansari \& Blier, 2006). Treatment for phobic disorders includes exposure therapy. Treatment for posttraumatic stress disorder includes antidepressants such as monoamine oxidase inhibitors, 
tricyclic antidepressants, and selective serotonin reuptake inhibitors (Dazzi, Seu, Cherchi, \& Biggio, 2005).

The purpose of the present study was to determine the effects of curcumin on anxiety and memory. We used the elevated plus maze (EPM), a standard behavioral model that can assess pentylenetetrazole (PTZ)-induced anxiety, in which the aversive behavior of rats in response to open and elevated areas is considered an index of anxiety. We also assessed memory retention using the passive avoidance task. The effect of curcumin on monoamine levels in the cerebral cortex, cerebellum, hypothalamus, hippocampus, and pons were estimated fluorimetrically (American Psychiatric Association [APA], 2001). Excitatory and inhibitory neurotransmitters have been reported to play a considerable role in the mediation of anxiolytic behaviors and cognitive tasks.

\section{Methods}

\section{Animals}

Inbred adult male Wistar rats (200-250 g) were obtained from the animal house of Bapatla College of Pharmacy (1032/ac/07/CPCSEA), Bapatla, India, and were housed at a constant room temperature $\left(22 \pm 1^{\circ} \mathrm{C}\right)$ and $40-50 \%$ relative humidity with a $12 \mathrm{~h} / 12 \mathrm{~h}$ light-dark cycle. Standard food pellets (Rayan's Biotech, Hyderabad, India) and water were provided ad libitum throughout the experimentation period. Animals were acclimated to the laboratory conditions 1 week prior to the initiation of the experiments. The experimental protocol was approved by the Institutional Animal Ethics Committee (IAEC/I-6/ BCOP/2007-2008), and all of the experiments involved in this work were performed in accordance with CPCSEA guidelines for the care and use of experimental animals.

To avoid variations in the results caused by the circadian rhythm of biogenic amine levels and their metabolism, all of the experiments, including the measurement of the biogenic amines, were conducted between 8:00 AM and 10:00 AM, 14 days after curcumin treatment.

\section{Drugs and drug administration}

Dopamine and NE were obtained from Sigma (St. Louis, MO,USA).Serotoninwas obtained fromQualigens (Mumbai, India). Diazepam (DZP) was obtained from Centaur Labs (Mumbai, India). Pentylenetetrazole was obtained from SD Fine Chemicals (Mumbai, India). Curcumin was obtained from Chemiloids (Laila Impex, Vijayawada, India).

Curcumin was characterized by $\mathrm{H}^{+}$nuclear magnetic resonance studies. For oral administration, curcumin was dissolved in peanut oil and diluted to the desired concentration (5 and $10 \mathrm{mg} / \mathrm{kg}$; p.o.) with peanut oil on the day of administration. Diazepam ( $3 \mathrm{mg} / \mathrm{kg}$; i.p.) was diluted with sterile saline. Pentylenetetrazole was dissolved in sterile saline to the desired concentration (20 mg/kg; i.p.). The peanut oil and sterile saline were used as control treatments, and the behavioral data did not differ between rats that received these vehicles. Therefore, the results were compared with the peanut oil (vehicle)-treated control group.

\section{Passive avoidance test: training and testing in normal rats}

The passive avoidance test was performed to determine memory-retentive effects in normal rats (Satyan, Rai, Jaiswal, Achrya, \& Bhattacharya, 1995). The test chamber comprised a rectangular box $(45 \mathrm{~cm} \times$ $30 \mathrm{~cm} \times 40 \mathrm{~cm}$ ) with a grid floor that could be electrified. An $8 \mathrm{~cm}$ high wooden platform was fixed to the grid floor at its center. Rats were divided into five groups ( $n=6$ per group) and were individually placed on the platform. Upon stepping down from the platform, the rats received a $0.5 \mathrm{~mA}$ footshock (duration, $3 \mathrm{sec}$.) and were then returned to the cage. Rats were trained twice daily for 2 weeks. The memory retention test was then performed in the same groups by placing the animals on the platform, and the step-down latency was scored to determine the inflexion ratio (IR): $I R=L_{1}-L_{0} / L_{0}$, where $\mathrm{L}_{0}$ is the step-down latency before the test and $\mathrm{L}_{1}$ is the step-down latency after the test.

\section{Animal groups}

Curcumin and DZP were administered for 14 days and 30 minutes prior to PTZ administration on the last day of treatment. Group 1 served as the control and received peanut oil ( $0.1 \mathrm{ml} / 100 \mathrm{~g}$; p.o.). Group 2 served as the negative control and did not receive any treatment. Groups 3 and 4 were treated with curcumin at doses of 5 and $10 \mathrm{mg} / \mathrm{kg}$; p.o., respectively. Group $\mathrm{V}$ was treated with DZP (3 mg/kg; i.p.) and served as the standard. These groups were used to study the effects on anxiety, PTZ-induced memory loss, and monoamine (5-HT, DA, and NE) levels in various regions of the brain.

\section{Elevated plus maze}

On the last day of drug treatment and 30 minutes after administration of test and standard drugs, PTZ (20 mg/kg; i.p.) was administered to all of the groups, with the exception of control rats, to induce anxiety-like behavior. Ten minutes after PTZ administration, animals were placed in the center of the EPM (Pellow, Chopin, File, \& Briley, 1985), which was elevated $50 \mathrm{~cm}$ above the floor, facing a closed arm and were observed for 5 minutes to record the duration of time spent in and number of entries into the open arms. The time spent in the center of the EPM was disregarded.

\section{Passive avoidance test after the EPM trial}

Each of the five groups of rats was subjected to the passive avoidance retention test after exposure to the EPM. Rats were placed on the raised platform in the middle of the grid, and the step-down latency was 
measured to evaluate the effects of curcumin and DZP on memory retention. The IR was then calculated.

\section{Estimation of catecholamines and indoleamines in rat brain}

Rats were sacrificed by cervical dislocation. Brains were quickly isolated, and the cerebral cortex, cerebellum, pons, hippocampus, and hypothalamus were dissected on an ice-cold flat glass plate. Anesthesia was not used because it alters brain monoamines levels (Ravindran, Rathinasamy, Samson, \& Senthilvelan, 2005). Concentrations of NE, DA, and 5-HT were measured by fluorimetry (Kari, Davidson, Kohl, \& Kochhar, 1978).

All brain regions were weighed, and the brain regions of two rats within the same group were pooled and homogenized with $6 \mathrm{ml}$ cold acidified butanol at $800 \times$ $g$. An aliquot from each homogenate pool served as the tissue sample for that group. The internal standards were prepared with the addition of known amounts of mixed standard (5-HT, NE, and DA; $500 \mu \mathrm{g}$ each) to a portion of homogenate pools and processed in parallel with the tissue samples. The reagent blanks and test samples for estimation were prepared following the same procedure described by Kari et al. (1978), with slight modifications. Serotonin, NE, and DA were read at excitation and emission wavelengths of $385 \mathrm{~nm}$ and $485 \mathrm{~nm}, 320 \mathrm{~nm}$ and $370 \mathrm{~nm}$, and $360 \mathrm{~nm}$ and $470 \mathrm{~nm}$, respectively, with a slit width of 10/10 nm.

\section{Statistical analysis}

The data obtained from the EPM are expressed as mean $( \pm$ SEM $)$, and the results from each group were compared with Group 2. The effects on memory retention after the EPM trial were compared with memory retention before PTZ administration using the paired $t$-test. The effects on anxiolytic-like behavior, memory retention, and monoamine levels between groups were analyzed using one-way analysis of variance (ANOVA). Significant effects in the ANOVA were followed by analyzing intergroup differences using Dunnett's $t$-test. Values of $p<.05$ were considered statistically significant.

\section{Results}

\section{Passiveavoidanceretentiontestbeforepentylenetetrazole} administration

The test for memory retention of the learned task (step-down latency) was performed after training, and all of the groups showed a significant increase in stepdown latency, indicating a memory-retentive effect in normal rats (Table 1).

\section{Elevated plus maze}

A significant decrease in the time spent on the open arms and the number of entries into the open arms was observed in Group 2. Rats pretreated with curcumin (5 and $10 \mathrm{mg} / \mathrm{kg}$ ) showed a significant increase in the time spent
Table 1. Effect on step-down latency before and after training in the passive avoidance retention task. Values are expressed as mean \pm SEM of step-down latency (s) of six observations. Values obtained after training were compared with before training using the paired $t$-test. ${ }^{\#} p<.001$.

\begin{tabular}{llcl}
\hline \multirow{2}{*}{ Group } & \multicolumn{2}{c}{ STEP-DOWN LATENCY } & \\
\cline { 2 - 3 } & $\begin{array}{c}\text { Before } \\
\text { training (s) }\end{array}$ & $\begin{array}{c}\text { After } \\
\text { training (s) }\end{array}$ & \multirow{2}{*}{$\begin{array}{c}\text { Ratio } \\
\text { Raion }\end{array}$} \\
\hline 1 & $9.58 \pm 2.4$ & $148.17 \pm 13.5^{\#}$ & 14.46 \\
2 & $8.36 \pm 1.8$ & $139.72 \pm 21.5^{\#}$ & 15.71 \\
3 & $6.71 \pm 1.2$ & $114.89 \pm 14.3^{\#}$ & 16.12 \\
4 & $12.89 \pm 4.6$ & $121.56 \pm 18.6^{\#}$ & 8.43 \\
5 & $6.83 \pm 1.9$ & $115.68 \pm 19.8^{\#}$ & 15.93 \\
\hline
\end{tabular}

Table 2. Effect of curcumin on anxiety-like behavior in the elevated plus maze. Data are expressed as mean \pm SEM of six observations, representing the duration of time spent in the open arms and number of open arm entries. a, comparison of Group 1 vs. Group 2; b, comparison of Group 2 vs. Groups 3,4 , and $5 ; * \mathrm{p}<.05, * * \mathrm{p}<.01,{ }^{*} \mathrm{p}<.001 ; \mathrm{ns}$, not significant. Pentylenetetrazole was administered to all of the groups, with the exception of the vehicle-treated control group.

\begin{tabular}{llll}
\hline Group & $\begin{array}{c}\text { Time spent on } \\
\text { open arms (s) }\end{array}$ & $\begin{array}{c}\text { Number of open } \\
\text { arm entries }\end{array}$ \\
\hline $1 \quad \begin{array}{l}\text { Vehicle-treated } \\
\text { control }\end{array}$ & $54.12 \pm 5.7$ & $13.2 \pm 1.4$ \\
2 & $\begin{array}{l}\text { Pentylenetetrazole } \\
14.6 \pm 1.2^{\mathrm{a} \#}\end{array}$ & $3.1 \pm 0.6^{\mathrm{a} \#}$ \\
3 & Curcumin $5 \mathrm{mg} / \mathrm{kg}$ & $22.2 \pm 3.1^{\mathrm{b} *}$ & $6.2 \pm 1.7^{\mathrm{bns}}$ \\
4 & $\begin{array}{l}\text { Curcumin } 10 \mathrm{mg} / \\
\mathrm{kg}\end{array}$ & $38.61 \pm 5.4^{\mathrm{b} * *}$ & $9.3 \pm 1.2^{\mathrm{b} * *}$ \\
5 & $\begin{array}{l}\text { Diazepam } \\
4\end{array}$ & $44.33 \pm 4.3^{\mathrm{b} *}$ & $11.5 \pm 2.5^{\mathrm{b} \#}$ \\
\hline
\end{tabular}

on the open arms and number of entries into the open arms compared with Group 2. The results from Group 4 were comparable to the DZP-treated rats (Table 2).

Passive avoidance retention test after pentylenetetrazole administration

Profound impairment in memory retention was observed in PTZ-treated rats compared with the control group. Curcumin $(10 \mathrm{mg} / \mathrm{kg})$ markedly increased stepdown latency. Diazepam-treated rats also showed a marked decrease in step-down latency. The effects of various treatments on memory retention are summarized in Table 3, and the IRs are shown in Figure 1.

\section{Effect on brain serotonin levels in different brain regions}

Monoamine levels in Groups 2, 3, 4, and 5 were compared with the control group (no PTZ administration). Curcumintreatment $(5 \mathrm{mg} / \mathrm{kg})$ increased 5 -HT levels in the cortex $(p<.05)$, hippocampus $(p$ $<.05)$, hypothalamus $(p<.05)$, and pons $(p<.01)$. The $10 \mathrm{mg} / \mathrm{kg}$ dose significantly increased 5 -HT levels 


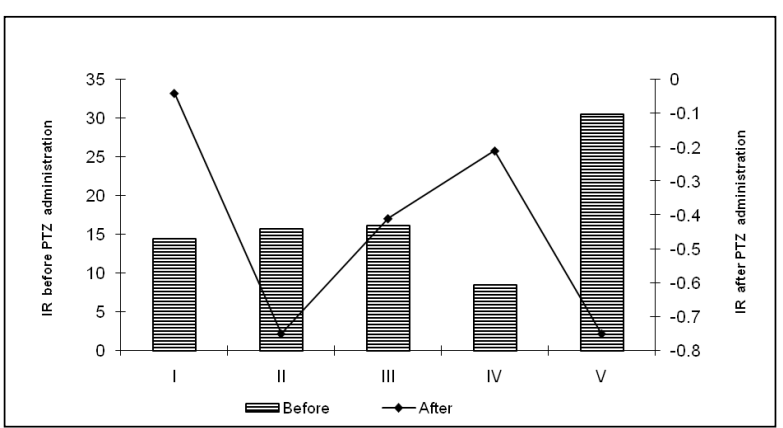

Figure 1. Histogram showing the effect on step-down latency inflexion ratios before and after PTZ administration.

in the cortex $(p<.001)$, hippocampus $(p<.001)$, and hypothalamus $(p<.001)$. In contrast, DZP treatment did not induce any significant changes compared with Group 2, with the exception of the cerebral cortex and hippocampus (Figure 2).

Effect on brain dopamine levels in different brain regions

A significant decrease in DA levels was observed in the cortex, hippocampus, hypothalamus, and pons in PTZ-treated rats $(p<.001)$. Rats treated with curcumin $(10 \mathrm{mg} / \mathrm{kg})$ showed a significant increase in DA levels in the cortex $(p<.05)$, hippocampus ( $p<.05)$, hypothalamus $(p<.01)$, and pons $(p<.001)$. Diazepam-treated rats showed a significant increase in the hippocampus $(p$ $<.001)$, hypothalamus $(p<.01)$, and pons $(p<.01)$. No significant change was observed in the cerebellum compared with PTZ-treated rats (Figure 3).

Effect on brain norepinephrine levels in different brain regions

A significant decrease in NE levels was observed in the hippocampus and hypothalamus in PTZ-treated rats $(p<.001)$. Curcumin $(10 \mathrm{mg} / \mathrm{kg})$ significantly increased NE levels in the cortex $(p<.001)$, hippocampus $(p$
Table 3. Effect of curcumin on step-down latency before and after pentylenetetrazole administration. Values are expressed as mean \pm SEM of six observations. Curcumin $(5$ and $10 \mathrm{mg} /$ $\mathrm{kg}$ ) and diazepam treatments were compared with controls. a, comparison of Group 1 vs. Group 2; b, comparison of Group 2 vs. Groups 3, 4, and 5; ${ }^{*} p<.05,{ }^{* *} p<.01,{ }^{*} p<.001$.

\begin{tabular}{|c|c|c|c|c|}
\hline \multirow{2}{*}{\multicolumn{2}{|c|}{ Group }} & \multicolumn{2}{|c|}{ STEP-DOWN LATENCY } & \multirow{2}{*}{$\begin{array}{l}\text { Inflexion } \\
\text { Ratio }\end{array}$} \\
\hline & & \multirow{2}{*}{$\begin{array}{l}\begin{array}{l}\text { Before PTZ } \\
\text { treatment (s) }\end{array} \\
148.17 \pm 4.5\end{array}$} & \multirow{2}{*}{$\begin{array}{l}\begin{array}{l}\text { After PTZ } \\
\text { treatment (s) }\end{array} \\
142.83 \pm \\
21.28\end{array}$} & \\
\hline 1 & Control & & & -0.04 \\
\hline 2 & $\begin{array}{l}\text { Pentylene- } \\
\text { tetrazole }\end{array}$ & $\begin{array}{l}139.72 \pm \\
21.5\end{array}$ & $34.5 \pm 5.76^{\mathrm{a} \#}$ & -0.75 \\
\hline 3 & $\begin{array}{l}\text { Curcumin } 5 \\
\mathrm{mg} / \mathrm{kg}\end{array}$ & $\begin{array}{l}114.89 \pm \\
14.3\end{array}$ & $67.3 \pm 1.05^{\text {bns }}$ & -0.41 \\
\hline 4 & $\begin{array}{l}\text { Curcumin } \\
10 \mathrm{mg} / \mathrm{kg}\end{array}$ & $\begin{array}{l}121.56 \pm \\
18.6\end{array}$ & $96 \pm 1.68^{\mathrm{b} * *}$ & -0.21 \\
\hline 5 & Diazepam & $\begin{array}{l}115.68 \pm \\
19.8\end{array}$ & $54.8 \pm 2.7^{\mathrm{b} *}$ & -0.52 \\
\hline
\end{tabular}

$<.001)$, hypothalamus $(p<.01)$, and pons $(p<.01)$. Diazepam-treated rats did not show any significant change in NE levels. No significant change in NE levels was observed in the cerebellum compared with PTZtreated rats, with the exception of Group 4 (Figure 4).

\section{Discussion}

In the present study, the effects of curcumin on anxiety-like behavior were evaluated using the EPM, and the effects of curcumin and DZP on memory retention after the induction of anxiety were assessed using the passive avoidance test. When rats were exposed to the

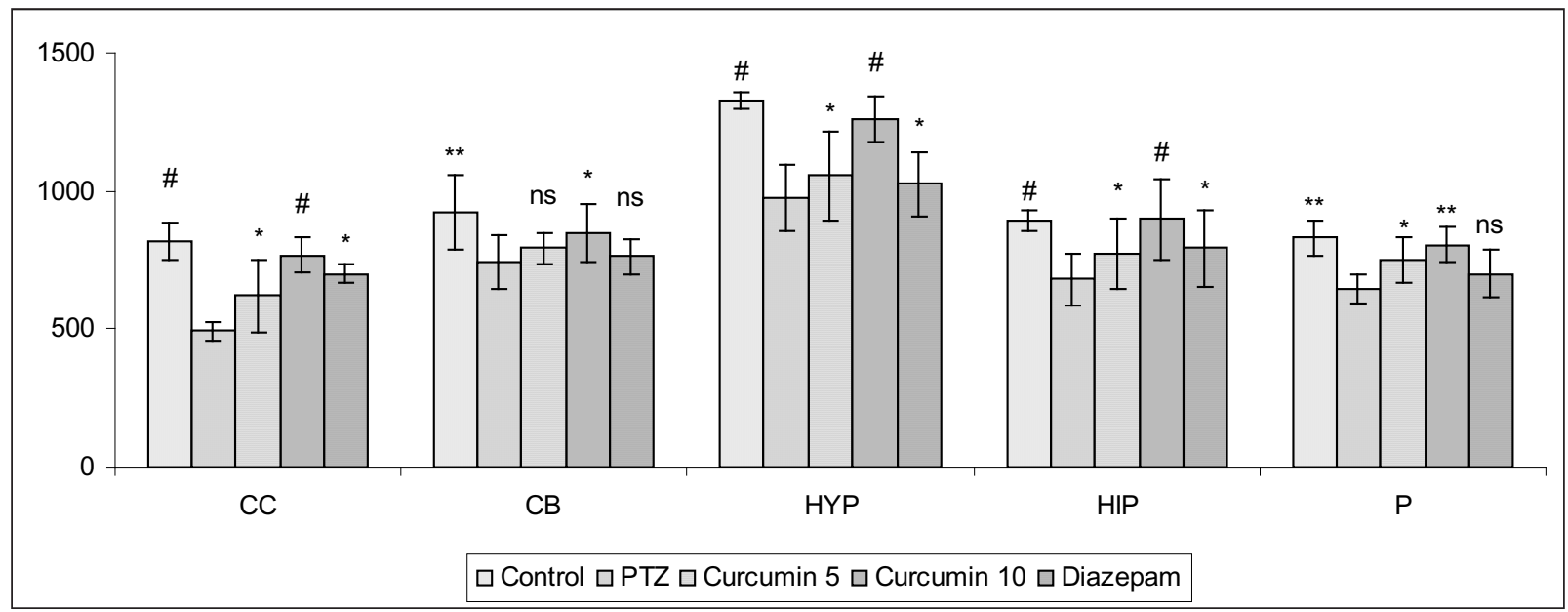

Figure 2. Histogram showing the effects of curcumin and DZP on 5-HT levels (ng/g of wet tissue) in various regions of rat brain (cerebral cortex [CC], cerebellum [CB], hypothalamus [HYP], hippocampus [HIP], and pons [P]) on the 14th day of treatment. Each column represents the mean \pm SEM of three samples. The brain regions of two rats of the same group were pooled. Control, $5 \mathrm{mg} / \mathrm{kg}$ curcumin, $10 \mathrm{mg} / \mathrm{kg}$ curcumin, and DZP values were compared with the PTZ group. Pentylenetetrazole was administered to all of the groups, with the exception of controls. 


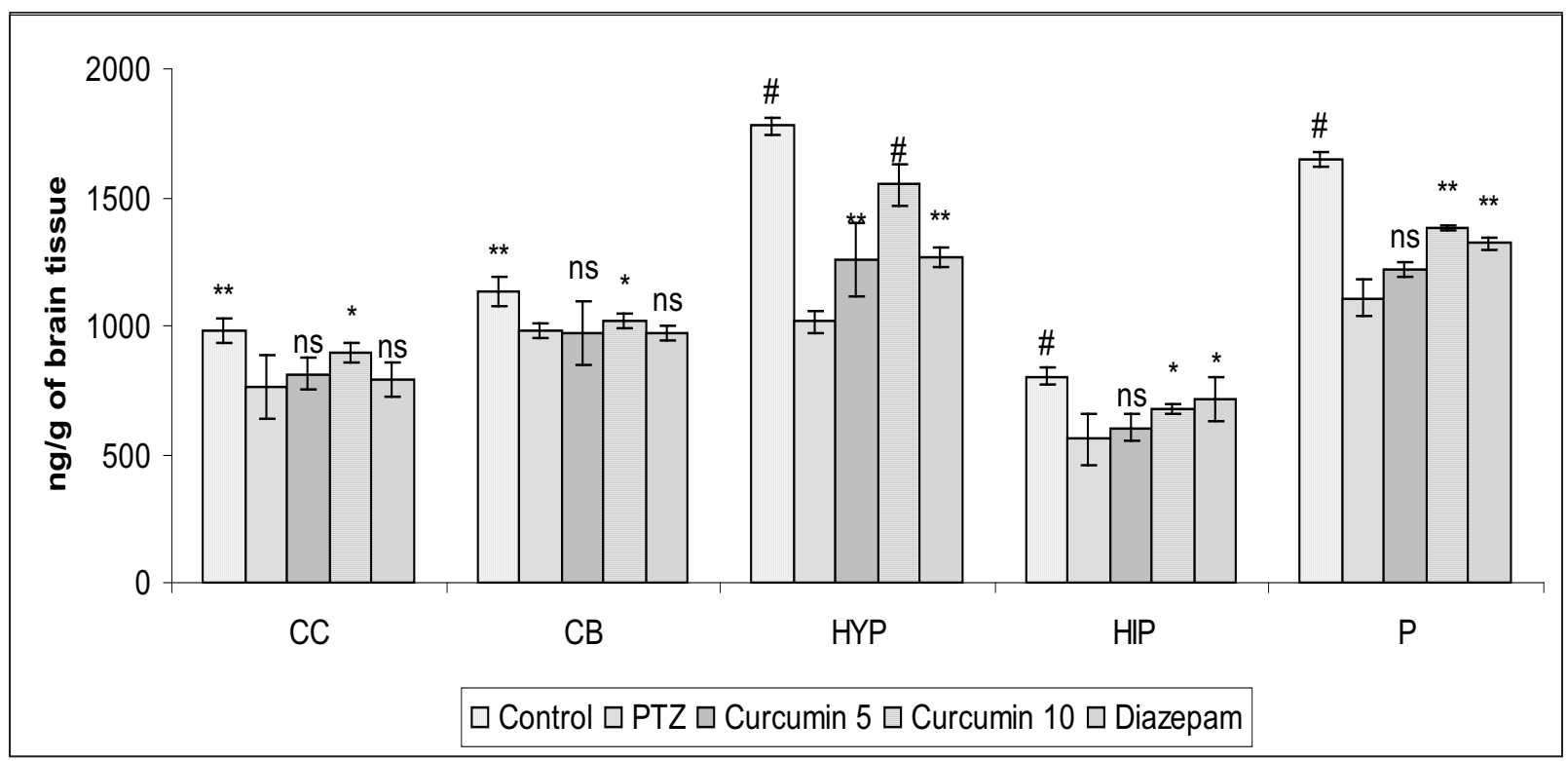

Figure 3. Histogram showing the effects of curcumin and DZP on dopamine levels (ng/g of wet tissue) in various regions of rat brain (cerebral cortex [CC], cerebellum [CB], hypothalamus [HYP], hippocampus [HIP], and pons [P]) on the 14th day of treatment. Each column represents the mean \pm SEM of three samples. The brain regions of two rats of the same group were pooled. Control, $5 \mathrm{mg} / \mathrm{kg}$ curcumin, $10 \mathrm{mg} / \mathrm{kg}$ curcumin, and DZP values were compared with the PTZ group. Pentylenetetrazole was administered to all of the groups, with the exception of controls.

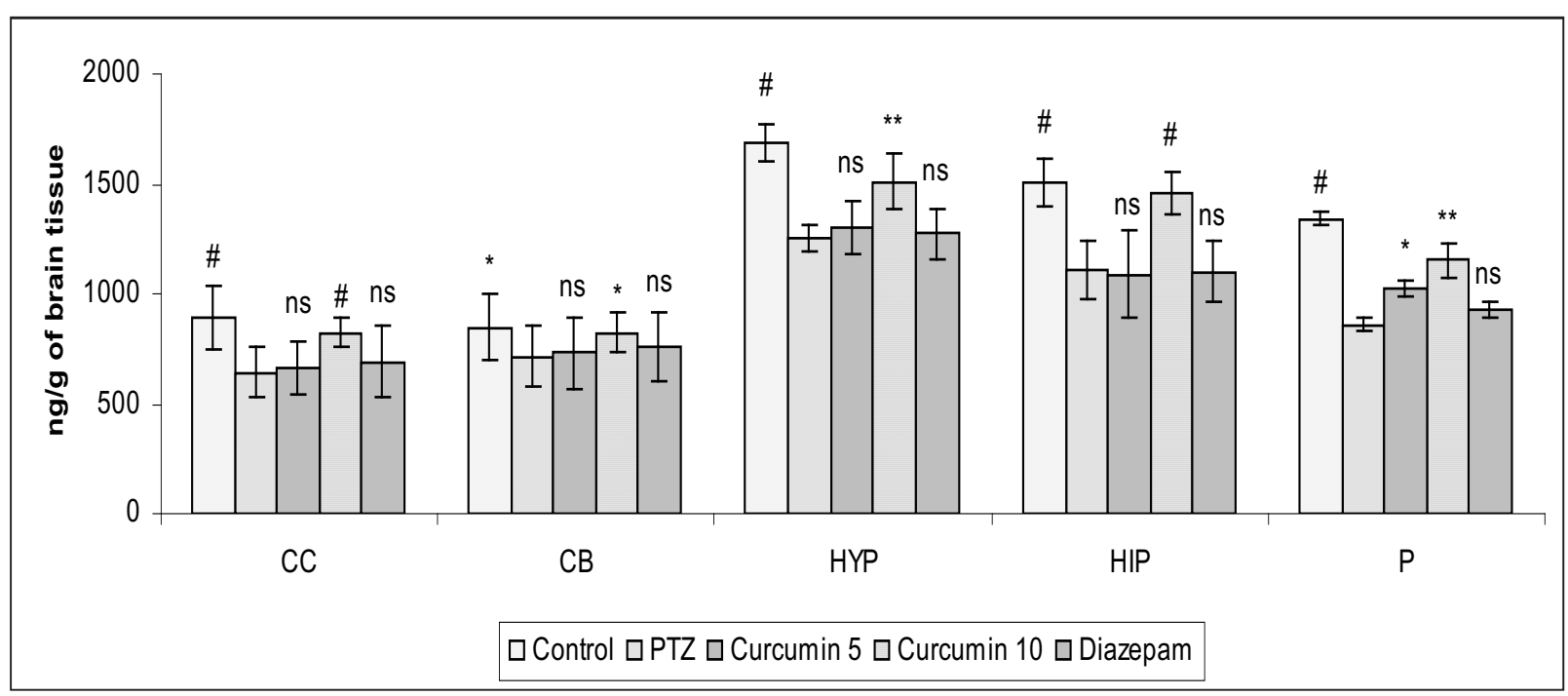

Figure 4. Histogram showing the effects of curcumin and DZP on NE levels (ng/g of wet tissue) in various regions of rat brain (cerebral cortex $[\mathrm{CC}]$, cerebellum $[\mathrm{CB}]$, hypothalamus [HYP], hippocampus [HIP], and pons $[\mathrm{P}]$ ) on the 14th day of treatment. Each column represents the mean \pm SEM of three samples. The brain regions of two rats of the same group were pooled. Control, $5 \mathrm{mg} / \mathrm{kg}$ curcumin, $10 \mathrm{mg} / \mathrm{kg}$ curcumin, and DZP values were compared with the PTZ group. Pentylenetetrazole was administered to all of the groups, with the exception of controls.

EPM, a significant increase in the time spent in the open arms and open arm entries, comparable to that of DZP treatment, was observed with curcumin treatment. These anxiolytic-like effects exerted by DZP were reflected by increased spatio-temporal measures, such as increased open arm entries and open arm time and decreased closed arm entries and closed arm time, which may be attributable to a facilitatory action on $\gamma$-aminobutyric acid (Goddard et al., 2001; Hobbs, Rall, \& Verdoorn, 1996). The present study suggests the importance of
5-HT in the etiology of anxiety and in the alteration of mood and cognitive function by its modulatory effects on the locus coeruleus (Ninan, 1999). Selective serotonin reuptake inhibitors have been used in the treatment of anxiety disorders, and the observed increase in 5-HT levels supports this clinical indication.

The possible mechanism involved in the anxiolyticlike effect of curcumin can be attributed to previously reported increases in 5-HT levels (Xu et al., 2005), which formed the basis for the present study. Serotonin 
acts on many pre- and postsynaptic 5-HT receptors. It acts on presynaptic 5-HT ${ }_{1 \mathrm{~A}}$ autoreceptors and decreases the neuronal firing of the serotonergic system. Serotonin also has a considerable stimulatory effect on postsynaptic 5-HT receptors, leading to receptor desensitization (Nutt et al., 1999). After considerable exposure, this mechanism can be attributed to the anxiolytic activity of curcumin (Nutt, 1998).

The increase in nootropic activity in curcumintreated rats may be attributable to increased DA (Roozendaal, 2002) and NE (Coull, 1994) turnover rates, which was demonstrated in the cortex and hypothalamus. These brain regions are involved in the regulation of cognition, mood, and performance, and Curcuma longa may exert its effects via inhibitory monoamine oxidase A and B activity in these regions ( $\mathrm{Yu}$ et al., 2002) which increases brain 5-HT, DA, and NE levels. Norepinephrine is suggested to play an important role in memory processing (Clayton \& Williams, 2000), and the potentiating effect of curcumin on NE levels may be attributable to the anxiolytic-like effect of curcumin.

In conclusion, the many putative mechanisms of action and broad spectrum of anxiolytic-like and memory-retentive effects of curcumin may be attributable to its effects on 5HT, DA, and NE levels. This possibility may be substantiated by examining the effects of curcumin on other potential neurotransmitters involved in the mediation of anxiety and dementia. Therefore, further studies are necessary to clarify the unique pharmacological profile of curcumin.

\section{References}

American Psychiatric Association (2001). SSRI's show promise as treatment for anxiety disorders in children. Psychiatric News, 36 (10), 14.

Aalto, S., Brück, A., Laine, M., Någren, K., \& Rinne, J.O. (2005). Frontal and temporal dopamine release during working memory and attention tasks in healthy humans: a positron emission tomography study using the high-affinity dopamine $\mathrm{D}_{2}$ receptor ligand $\left[{ }^{11} \mathrm{C}\right] \mathrm{FLB}$ 457. Journal of Neuroscience, $25,2471-2477$.

Cassano, G.B., Pini, S., Saettoni, M., \& Dell'Osso, L. (1999). Multiple anxiety disorder comorbidity in patients with mood spectrum disorders with psychotic features. American Journal of Psychiatry, 156, 474-476.

Clayton, E.C., \& Williams, C.L. (2000). Adrenergic activation of the nucleus tractus solitarius potentiates amygdala norepinephrine release and enhances retention performance in emotionally arousing and spatial memory tasks. Behavioural Brain Research, 112, 151-158.

Coull, J.T. (1994). Pharmacological manipulations of the $\alpha 2$-noradrenergic system: effects on cognition. Drugs and Aging, 5, 116-126.

Dazzi, L., Seu, E., Cherchi, G., \& Biggio, G. (2005). Chronic administration of the SSRI fluvoxamine markedly and selectively reduces the sensitivity of cortical serotonergic neurons to footshock stress. European Neuropsychopharmacology, 15, 283-290.
El Mansari, M., \& Blier, P. (2006). Mechanisms of action of current and potential pharmacotherapies of obsessive-compulsive disorder. Progress in Neuropsychopharmacology and Biological Psychiatry, 30, 362-373.

Eysenck, M.W., \& Calvo, M.G. (1992). Anxiety and performance: the processing efficiency theory. Cognition and Emotion, 6, 409-434.

Ferry, B., Roozendaal, B., \& McGaugh, J.L. (1999). Role of norepinephrine in mediating stress hormone regulation of longterm memory storage: a critical involvement of the amygdala. Biological Psychiatry, $46,1140-1152$.

Goddard, A.W., Mason, G.F., Almai, A., Rothman, D.L., Behar, K.L., Petroff, O.A., Charney, D.S. \& Krystal, J.H. (2001). Reductions in occipital cortex GABA levels in panic disorder detected with ${ }^{1} \mathrm{H}-$ magnetic resonance spectroscopy. Archives of General Psychiatry, $58,556-561$.

Hobbs, W.R., Rall, T.W., \& Verdoorn, T. (1996). Hypnotics and sedatives: ethanol. In J.G. Hardman \& L.E. Limbird (Eds.), Goodman and Gillman's The Pharmacological Basis of Therapeutics, (9th ed., pp. 364-367). New York: McGraw-Hill.

Kari, H.P., Davidson, P.P., Kohl, H.H., \& Kochhar, M.M. (1978). Effects of ketamine on brain monoamine levels in rats. Research Communications in Chemical Pathology and Pharmacology, 20, 475-488.

Ninan, P.T. (1999). The functional anatomy, neurochemistry, and pharmacology of anxiety. Journal of Clinical Psychiatry, 60 ( Suppl 22), 12-17.

Nutt, D.J. (1998). Antidepressants in panic disorder: clinical and preclinical mechanisms. Journal of Clinical Psychiatry, 59 (Suppl 8), 24-28.

Nutt, D.J., Forshall, S., Bell, C., Rich, A., Sandford, J., Nash, J., \& Argyropoulos, S. (1999). Mechanisms of action of selective serotonin reuptake inhibitors in the treatment of psychiatric disorders. European Neuropsychopharmacology, 9 (Suppl 3), S81-S86.

Pellow, S., Chopin, P., File, S.E., \& Briley, M. (1985). Validation of open: closed arm entries in an elevated plus-maze as a measure of anxiety in the rat. Journal of Neuroscience Methods, 14, 149-167.

Ravindran, R., Rathinasamy, S.D., Samson, J., \& Senthilvelan, M. (2005). Noise-stress-induced brain neurotransmitter changes and the effect of Ocimum sanctum (Linn) treatment in albino rats. Journal of Pharmacological Sciences, 98, 354-360.

Ringman, J.M., Frautschy, S.A., Cole, G.M., Masterman, D.L., \& Cummings, J.L. (2005). A potential role of the curry spice curcumin in Alzheimer's disease. Current Alzheimer Research, 2, 131-136.

Roozendaal, B. (2002). Stress and memory: opposing effects of glucocorticoids on memory consolidation and memory retrieval. Neurobiology of Learning and Memory, 78, 578-595.

Satyan, K.S., Rai, A., Jaiswal, A.K., Acharya, S.B., \& Bhattacharya, S.K. (1995). Isatin, a putative anxiogenic endocoid, induces memory dysfunction in rats. Indian Journal of Experimental Biology, 33, 576-579.

Sharma, P.C., Yelne, M.B., Dennis, T.J., Joshi, A., \& Billore, K.V. (2002). Database on medicinal plants used in ayurveda. New Delhi: Central Council for Research in Ayurveda and Siddha.

Wesolowska, A., \& Nikiforuk, A. (2007). Effects of the brain-penetrant and selective 5-HT ${ }_{6}$ receptor antagonist SB-399885 in animal models of anxiety and depression. Neuropharmacology, 52, 1274-1283.

Xia, X., Cheng, G., Pan, Y., Xia, Z.H., \& Kong, L.D. (2007). Behavioral, neurochemical and neuroendocrine effects of the ethanolic extract from Curcuma longa L. in the mouse forced swimming test. Journal of Ethnopharmacology, 110, 356-363.

Xu, Y., Ku, B.S., Yao, H.Y., Lin, Y.H., Ma, X., Zhang, Y.H. \& Li, X.J. (2005). Antidepressant effects of curcumin in the forced swim test and olfactory bulbectomy models of depression in rats. Pharmacology Biochemistry and Behavior, 82, 200-206.

Yu, Z.F., Kong, L.D., \& Chen, Y. (2002). Antidepressant activity of aqueous extracts of Curcuma longa in mice. Journal of Ethnopharmacology, 83 (1-2), 161-165. 